ARTICLE

\title{
Developing a Citizen Social Science approach to understand urban stress and promote wellbeing in urban communities
}

\author{
Jessica Pykett ${ }^{\boxplus}$, Benjamin Chrisinger (D) ${ }^{2}$, Kalliopi Kyriakou (D) ${ }^{3}$, Tess Osborne (D) ${ }^{4}$, Bernd Resch ${ }^{3}$, \\ Afroditi Stathi ${ }^{1}$ Eszter Toth $^{1} \&$ Anna C. Whittaker ${ }^{5}$
}

\begin{abstract}
This paper sets out the future potential and challenges for developing an interdisciplinary, mixed-method Citizen Social Science approach to researching urban emotions. It focuses on urban stress, which is increasingly noted as a global mental health challenge facing both urbanised and rapidly urbanising societies. The paper reviews the existing use of mobile psychophysiological or biosensing within urban environments-as means of 'capturing' the urban geographies of emotions. Methodological reflections are included on primary research using biosensing in a study of workplace and commuter stress for university employees in Birmingham (UK) and Salzburg (Austria) for illustrative purposes. In comparing perspectives on the conceptualisation and measurement of urban stress from psychology, neuroscience and urban planning, the difficulties of defining scientific constructs within Citizen Science are discussed to set out the groundwork for fostering interdisciplinary dialogue. The novel methods, geo-located sensor technologies and data-driven approaches to researching urban stress now available to researchers pose a number of ethical, political and conceptual challenges around defining and measuring emotions, stress, human behaviour and urban space. They also raise issues of rigour, participation and social scientific interpretation. Introducing methods informed by more critical Citizen Social Science perspectives can temper overly individualised forms of data collection to establish more effective ways of addressing urban stress and promoting wellbeing in urban communities.
\end{abstract}

\footnotetext{
${ }^{1}$ University of Birmingham, Birmingham, UK. ${ }^{2}$ University of Oxford, Oxford, UK. ${ }^{3}$ University of Salzburg, Salzburg, Austria. ${ }^{4}$ University of Groningen, Groningen, The Netherlands. ${ }^{5}$ University of Stirling, Stirling, UK. ${ }^{凶}$ email: j.pykett@bham.ac.uk
} 


\section{Introduction: the case for interdisciplinary Citizen Science-utopian and dystopian data futures of affective capture}

Decent years have seen the emergence of a range of innovative and interdisciplinary efforts to better understand the dynamic relationships between human experience and urban environments. Citizen Science approaches are increasingly prevalent in this field. As a result of accelerating and widespread global urbanisation, there is increased interest in the effects of living in cities on human behaviour, health and wellbeing. Some of this research has focussed specifically on people's behaviour, including what kind of human actions are prompted by particular kinds of environmental cues (Hollands et al., 2013; Thaler and Sunstein, 2008). Other research has considered how spatial arrangements, architecture and urban design affect our memory, attention, decision-making or cognitive processes (Marquardt, 2011; Zeisel, 2006). A consideration of urban emotions has informed work ranging from studies tracking emotional responses to specific urban environments (Bergner et al., 2013; Birenboim, 2018; Birenboim et al., 2019; Shoval et al., 2018; Zeile et al., 2016), to others focussed on specific emotions such as happiness (MacKerron and Mourato, 2013), or fear (Culyba et al., 2019).

The mental health impact of city dwelling has also received particular attention, shedding new light on the intimate, intensive, and potentially psychologically damaging experience of urban places at varying stages of development (Bhugra et al., 2019; Corcoran et al., 2017; Lederbogen et al., 2011; Vassos et al., 2012). Social science and humanities researchers have also provided extensive insights on social relations in the city as a public sphere, including how these shape emotional encounters, experiences of social isolation or connectedness, community cohesion, intercultural dialogue and affective politics (Amin, 2013; Richaud and Amin, 2019; Piekut and Valentine, 2017; Simonsen, 2007; Wilson, 2017). Yet productive collaboration between behavioural and social scientists or humanities scholars on the topics of urban emotions and urban stress remains relatively rare. Such collaboration has the potential to radically question the status of the research 'subject' as an active participant in the production of scientific knowledge.

Nevertheless, among this diversity of perspectives, a question, which has a long history in both urban sociology and environmental psychology, and remains a shared pre-occupation is how it is, exactly, that cities sometimes unravel people?' (Schroeder, 1942 cited in Fitzgerald et al., 2017, p. 222). Whether we want to focus on personal or community wellbeing, emotional stimulation, urban environmental stressors, experiencing positive emotions or the specific unravelling of mental health, the causal pathways between urbanicity and emotions continue to be a matter of significant debate. It is thus proposed that novel kinds of analysis combining the biological and social sciences-a 'biosocial' approach (Manning, 2019; Meloni et al., 2018; Rose, 2013) or 'interdisciplinary entanglements' between the social and neurosciences-are required (Fitzgerald and Callard, 2014). These would have the potential to address an urgent and welldocumented global mental health challenge (WHO, 2017) and a demand for globally relevant urban policies to enhance emotional wellbeing (WHO, 2018). In this context, this paper explores the potential of an interdisciplinary research approach, which uses Citizen Science methods to understand embodied emotional experiences of urban life.

The potential for shaping a biosocial approach to understanding urban experience has been accelerated by the rapid development of personal and mobile digital technologies and applications in the field of wearable 'emotion sensors' and biosensors. Over the past decade, software engineers, designers, researchers and technology companies have created numerous devices, which either aim to provide users with real-time feedback on their emotional state(s), or to provide the means to record emotions from individuals and large populations in space and time. The unparalleled popularity and market expansion of consumer-ready devices means that opportunities to involve of citizens using their own wearable devices in the pursuit of Citizen Science research on urban emotions are being enthusiastically embraced by people who engage in self-tracking practices (the 'quantified self movement) (Swan, 2012).

New alliances between technology companies, urban engineers, planners and life scientists offer technological and engineered utopian solutions to tackle complex urban social problems (Camargo et al., 2018). However, concerns are frequently raised about the potential for self-tracking practices to develop deep divisions between those with science and technology expertise, commercial data owners and citizens (Beer, 2018; Ruppert, 2012), state paternalist practices, distributed forms of control and anticipation, to the diminution of citizenship rights (Cardullo and Kitchin, 2019). This wider societal context needs to be taken into account in developing research methodologies and involvement of citizen scientists in urban research.

Alongside this, the scientific concepts and models on which emotion tracking software and hardware rely are not well established. Not least, the idea of an emotion or feeling is a highly contested one, with contrasting definitions stemming from different disciplines, and varying from popular usage of the term. As such, researching emotions necessitates a multi-disciplinary approach. Emotions are not simply hiding in the body waiting to be experienced by individuals or discovered by scientists. The history of emotion research, and emotion science specifically is fraught with definitional disagreements (Plamper, 2012), and there is little consistent evidence that discrete emotions each have a distinct biomarker (Kreibig, 2010; Norman et al., 2016). This ambiguity gives researchers reasons to be cautious in establishing rigorous and valid study protocols in the field of technologyenabled and Citizen Science urban emotions research.

Disciplinary pluralism and conciliation should inform a more democratic form of Citizen Social Science, and the case for this is evident in the example of current studies on urban stress. Often the concept of 'stress' is identified as the key conduit between emotional or mental experience and the physical and social environment of the city. Within laboratory research, neuroscientists have reported on links between urban upbringing, city living and people's biological stress response mechanisms (Lederbogen et al., 2011). Laboratory-based mental stress tasks have been used to ascertain the mediating effects of city environments on stress (Olafsdottir et al., 2017; Steinheuser et al., 2014). Psychophysiologists have also developed ambulatory assessment methods, based on patient-reported data collection in naturalistic settings. They note that 'real-life stress can be much more intense than observed in the laboratory' (Wilhelm and Grossman, 2010, p. 554). Such studies have used a combination of electronic diaries, questionnaire data and physiological indicators to give 'situational specificity' (subjective, contextual data) to otherwise generalised accounts of emotional arousal or stress intensity (ibid., p. 561). This work addresses the concept of stress as a physiological response to particular events or environments, measured through biophysical outcomes in the autonomic nervous system (ANS), part of the nervous system that unconsciously regulates several of the body's physical functions.

One key challenge of working across disciplines is designing Citizen Science methodologies that adequately integrate 
physiological approaches with social science and humanities perspectives on urban stress. For instance, how can our approaches to Citizen Science both take advantage of the novel capacity and future promise of real-time physiological 'emotion sensing', as well as historically contextualising the concept of stress itself, and letting in room for interpretive research strategies? As historians and biomedical anthropologists have demonstrated, stress is a historically specific concept dependent on the social, governmental and economic purpose attributed to the psychological sciences themselves (Jackson, 2013).

It is easy to see how biological and physiological measures have become appealing as proxy measures of human emotional responses to urban environments. They offer a sense of objectivity and replicability not necessarily shared or desired by highly contextualised or more theoretical sociological research. Urban emotion sensing research has been dominated by approaches based largely on physiological accounts of stress. For instance, using biosensors to measure indicators of moments of stress (ECG, skin conductance, skin temperature and heart rate variability) among cyclists in Boston, USA (Zeile et al., 2016). Zeile et al. used the 'People as sensors' mobile application to gather this data alongside subjectively reported emotions, and analysed it spatially to develop maps of distinct emotions such as fear and anger, to inform urban planning on cycling safety. Similarly, Werner et al. (2019) have developed a mixed-methods approach to evaluate urban bicycle infrastructures, involving biosensors, an eDiary app and qualitative questionnaires.

Geographers have used commercially available wearable sensors to measure these biomarkers alongside GPS (global positioning system) signals, which locate people walking through different kinds of urban environments and infer participants' mental states (Birenboim et al., 2019; Shoval et al., 2018). Environmental psychologists have measured salivary cortisol levels among deprived urban populations living with differential access to green space (Ward Thompson et al., 2012; Roe et al., 2013). Some of these studies draw on some quite traditional methods from qualitative GIS and participatory mapping research such as asking research participants to report on their surroundings and momentary experiences in natural settings (e.g., King et al., 2016). Their novelty is in integrating this kind of research with methods, which assess people's bodily reactions to places using wearable technologies or biological samples.

The use of wearable sensors raises new possibilities for mobilising the capacity of large numbers of research participants to gather their own personal, biological and location-specific data, moment-by-moment. In so doing, such methods generate new conceptual, ethical and practical concerns about how to build in critical social science perspectives, as well as how to enable citizen engagement and participation in embodied urban emotion research. Wearable technologies are not scientifically neutral. The discursive and material imaginaries underpinning these devices shape our intimate processes of identity formation and can lead to a mistrust of experiential knowledge. They 'offer a particular precision in externalising, monitoring, and interpreting bodily processes that are assumed to be unavailable for experiential interpretation and management' (Berg, 2017, p. 2).

These concerns need to be addressed to avoid the advent of a dystopian reality in which our emotions are 'captured' by experts, commodified by private companies and become subject to unsolicited behavioural modification and machinic intervention, where we find satisfaction only in remaining neatly within the parameters of our various graphs' (Barker, 2017, p. 4)-one where personal narrative and reflection, as well as social scientific and humanities 'interpretations' are devalued. How can Citizen Social Science, therefore, navigate some of the tensions posed by the drive towards mobile urban stress measurement in light of social scientific accounts of self-tracking?

\section{Measuring urban emotions: multiple forms of expertise or instrumental intimacies?}

The advent of digital wearable technologies has invited much critical commentary, as novel forms of 'instrumental intimacy', which require us visualise, monitor, track and optimise our mental and emotional states, demanding us to 'subject ourselves to the oversight of various (medical) experts' (Littlefield, 2018, p. 3). Therefore, if we are to take seriously the imperative to value the expertise of research participants through Citizen Social Science, it is necessary to consider the ways in which the basic concepts under scrutiny are (a) defined and measured within different disciplinary perspectives, and (b) manifest in the very subjectivities whose 'objective' emotional experiences we may wish to capture through biosensing methods. In other words, the instruments through which we might research urban emotions and urban stress are already part of the social and subjective life that we wish to study. They herald an accelerated pace of life, and can instigate new forms of alienation from the self and collective life. As such, it is a distinctly political move to shift responsibility for emotional coping, recovering and stress alleviation to individuals acting in tandem with their personal technologies (Berg, 2017) and a Citizen Social Science needs to be sensitive to these dynamics. By considering the conceptualisation of stress within the different disciplinary traditions of the co-authors of this paper (Psychology, Behavioural Medicine, Neuroscience, Human Geography and Urban Planning), we can shed some light on how particular measurement strategies come to be used.

Psychological stressors and appraisal theories. Influencing Psychology and Behavioural Medicine, for example, early conceptualisations by physiologists such as Cannon and Selye focussed on the 'fight or flight' physiological stress response. The body responds to external threat, be it physical and/or psychological with a physiological response (Cannon, 1932; Selye, 1964). In this way, stress can be considered to be an environmental (internal or external) event, which perturbs the body's homoeostasis (Carroll, 1992). However, this approach assumes that all stressors result in an automatic consistent response regardless of the stressor type.

In Psychology, the conceptualisation of stress expanded to include a useful taxonomy of different types of stressor, varying by their intensity, duration, and the number of individuals affected (Lazarus and Cohen, 1977). The most severe category of events in this taxonomy is cataclysmic events such as natural disasters severely affecting a large number of individuals for considerable time. Secondly, life events such as bereavement or moving house were categorised as somewhat less severe but still with significant long-lasting impact for the individual. The final category is that of daily hassles, such as losing one's keys, or hitting bad traffic, which affect many of us frequently, but their impact is less chronic. This model of what stress is, and how severe it is, provides a checklist for measuring stress, and introduces a focus on temporality, which is not necessarily well served by the moment-by-moment psychophysiological stress measures pursed through biosensing.

Early stress measurement approaches included the self-report schedule of recent experiences (Holmes and Rahe, 1967), including stressors varying in duration. However, this approach assumes that stressful life events are objective and experienced in the same way by everyone, and does not take into account the individual's appraisal of the event, its perceived severity or desirability, or how much control an individual has over the 
event. Clearly individuals differ considerably in appraisals of the same event, so this needs to be taken into consideration in the measurement of stress. The transactional model of stress (Lazarus and Folkman, 1984) takes the individual appraisal of stress into account, and defines it as something, which is perceived as exceeding one's perceived ability to cope. Adaptations of the Holmes and Rahe scale have utilised techniques such as (a) weightings of stressful events (based on normative data from large samples) to account for the severity of different events, and (b) ratings of stressfulness, to take into account the different appraisals of the severity of different events.

A different approach has focused specifically on the perceptions of how stressful one's life currently is/has been recently, rather than assessing the occurrence of specific life events. For example, the Perceived Stress Scale (Cohen et al., 1983) focuses on the current experience of stress, and how uncontrollable, unpredictable, and overloaded respondents are finding their lives. This makes it useful for assessing individual responses to stressors but less useful for understanding the pathways between environmental stimulus and stress response.

Other psychological theories of stress have concerned themselves with related concepts such as mastery, resilience, and selfefficacy among others. All of these approaches are not without difficulties as they assume that individuals are always consciously aware of their own appraisals of stress, whereas this process may not always reach the level of awareness. Given these layers of complexity, it is not surprising that there is no one definition of stress within the field of Psychology. Given that stress is a psychological as well as physiological phenomenon, only a combination of methodologies is likely to give the most holistic view of stress. Understanding this complexity in stress definition and measurement may allow researchers to choose a variety of suitable methods through which Citizen Social Scientists can conceptualise, capture and interpret the experience of stress.

Biomarkers of stress. In the field of Neuroscience, there has been a drive to address the limitations of psychometric surveys and individual appraisal, to overcome the potential subjective biases and personal definitions of stress held by research participants. Neuroscience has shifted from directly interacting with participants towards more objective measures and biomarkers, such as cortisol levels. Cortisol is produced by the HypothalamicPituitary-Adrenal (HPA) axis in response to stress without any control by participants (Fries et al., 2009; Hellhammer et al., 2009). Owing to diurnal changes, cortisol levels are not easily applicable to measure the short-term consequences of city exposures (Mavros et al., 2016). However, they have proven useful for measuring the long-term consequences. Steinheuser et al. (2014) found that adults with an urban upbringing have a larger cortisol increase in response to a lab-based stress test, compared to adults with a rural upbringing, reflecting stronger stress response and perhaps increased stress levels of city dwellers. Moreover, urban upbringing was associated with a reduced cortisol awakening response (an elevation is usual when people wake up), which suggests a long-term effect of urban upbringing on HPA axis activity (Steinheueser et al., 2014, p. 682).

Functional magnetic resonance imaging (fMRI) is another technique that neuroscientists use to measure the effects of urban environments on stress responsivity. fMRI measures the amount of oxygen used by the different brain regions, showing which regions are more active in one condition than the other (e.g., after urban versus rural exposures). Using this technique, Lederbogen et al. (2011) showed that current city dwellers have a stronger amygdala response to social stress than current rural dwellers. The amygdala is a key region for activating the HPA axis
(Feldman et al., 1995). As the strength of the amygdala's activity signals the emotional intensity of an event (Lewis et al., 2006; Phan et al., 2004), Lederbogen et al.'s (2011) findings suggest that city dwellers perceive social stress more stressful than rural dwellers. This increased amygdala reactivity after city exposure might explain why people feel more stressed after a walk in a city compared to a natural, green area.

Despite the advantages of fMRI in terms of high-spatial resolution and biological precision, the scanners used are of course large, expensive and static. Therefore, they cannot be used to see what is happening in the brain at the time of the exposure to a particular environmental stressor, and their feasibility for Citizen Science research is limited. This explains why the advent of portable digital technologies and the increasingly common use of them by consumers has been so appealing to urban researchers. Electroencephalography (EEG), on the other hand, is a small and transportable, allowing participants to walk in a city while their brain activity is recorded via electrodes placed on the scalp (Berger, 1929; Mavros et al., 2016). Therefore, EEG allows neuroscience to overcome its main limitation; artificial experimental conditions, and is set to become a prevalent method in studies of urban stress and emotional response.

Using this technique, Aspinall et al. (2015) and Al-Barrak et al. (2017) provided objective evidence that people are less relaxed in an urban compared to a natural environment. This lack of opportunity to relax in cities could be one of the reasons urban living in both childhood and adulthood increases people's stress response. Such studies mark the beginning of a shift towards science carried out in more realistic environments. Yet in focussing on either urbanicity as defined by population size, or the physical properties of urban spatial forms, the neuroscientific approach tends not to fully address the social determinants of stress, the subjective meanings of emotions, or the city as a political and public sphere. Social science perspectives can potentially address these gaps, reminding us of the complexity of defining the most basic components of urban stress research, namely what stress, the body, physiology and emotions even are.

The exposome and embodied emotions. Health Geographers, for example, consider stress to be a pathogenic quality that can arise from multiple environmental factors operating at different scales, including economic status, housing conditions, educational attainment, access to services, among others (Curtis et al., 2007). Thus, for geography stress is an ambiguous term that can be considered both an emotional and social state that arises from a variety of social determinants, including the individual's context or the socio-ecological features of a place. These factors are not directly observable or experienced in the momentary assessment of stress responses enabled by biosensing technologies. Instead contemporary health geography advances a lifecourse account of stress (the exposome), which considers 'the long-term, accumulated imprints of exposure' to health risk factors and stressors (Prior et al., 2018, p. 2). Epidemiological studies advancing a 'biosocial' approach offer a route forward to make connections between socio-spatial inequalities and allostatic load; the spatially differential impact on the body of chronic exposure to stress (Prior et al., 2018, p. 8).

Long running debates on how to conceptualise place, context and space in health geography are now reflected in an approach to biodata, which considers the 'signature of socially patterned histories of experience, offering insight into mechanisms by which vulnerable populations may be constrained to lifecourses of ill health' (Prior et al., 2018, p. 8). This research approach relies on access to large health data sets and specialist data analysis skills of statistical and spatial modelling. It has not yet adopted 
Citizen Science approaches, though interdisciplinary teams have considered the potential for combining environmental sensor (rather than biosensor) methods to refine the exposome concept (Loh et al., 2017).

Where health geography has often focussed on the socio-spatial determinants of ill-health, cultural geographers have elaborated on the emotional experiences of distress and mental illness in ways, which could be useful for furthering understanding of urban stress. As Davidson and Milligan (2004, p. 524) have highlighted, emotions 'might be seen as a form of connective tissue that links experiential geographies of the human psyche and physique with(in) broader social geographies of place'. The notions of embodiment and emotions pursued in this work are not reducible to physiological responses but are concerned with the situationally and structurally specific meaning-making of diverse social groups, whose bodily characteristics and the embodied imbrication of social relations (race, gender, sexuality, (dis)ability) shape their experiences of urban environments.

Such an account of embodiment necessitates narrative interview-based methods, but researchers have not to date engaged substantially with physiological methods, notwithstanding frequent calls to pay attention to the 'fleshy' materiality of bodies (Hall, 2005). Yet, to approach emotions without attention to the historical specificity of the intersections between bodies, technologies and subjectivities, as Callard points out, would be to neglect the ways in which the meanings of urban distress have changed over time (Callard, 2003), and to mistakenly abstract our epistemologies of the body from the social, economic and political contexts in which we understand ourselves (Callard, 1998).

Stress in the urban public sphere. For Urban Planners, the incorporation of emotions marks a welcome change for a discipline, which has long struggled with how they are manifest in both individuals and communities, planners and lay-publics, and how emotions shape planning processes and decisions (Sandercock, 2004). This struggle has resulted in the side-lining of emotions by planners as un-scientific and even antithetical to broader aspirations to achieve 'rational,' comprehensive plans: 'Emotion has been rigorously purged, as if there were no such things as joy, tranquility, anger' (Sandercock, 2003). Sandercock (2004) argues that purging emotion from planning 'precludes the possibility of understanding the nature of much conflict in the city, conflict that is generated by fears and hopes, anxieties and desires, memory and loss, anger about and fear of change'.

While emotion may have been traditionally driven from mainstream Western planning paradigms, as an applied discipline, it is replete with practical and theoretical examples of urban designs created in response to perceived environmental stressors and stress experiences of inhabitants. Finding adequate ways to define and measure urban emotions and urban stress is therefore of importance. The carefully planned 'Garden Cities' of Ebenezer Howard, one of the intellectual founders of town planning in the UK, offered a utopian vision for new urban developments outside of what he viewed as chaotic, disorderly, stressful, and polluted urban centres of late nineteenth-century Britain. These connected residents to the benefits of town and country without their attendant social and environmental stressors (e.g., 'foul air,' 'excessive hours' and 'slums and gin palaces' in the city; 'lack of amusement,' 'lack of drainage,' and 'no public spirit' in the country) (Howard and Mumford, 1965). These kinds of moral ideals and values-rather than evidence from citizens-established the rationale for urban planning practice, and such ideas have been readily adapted and replicated by urban designers across the world seeking to justify plans to improve upon prevailing urban conditions (Corburn, 2004; Hall, 2014).

The belief that certain built environments can engender more salubrious, productive, or otherwise positive behaviours, what Corburn calls 'moral environmentalism', punctuates the practical and theoretical histories of city planning and urbanism (Corburn, 2004). Still, planners' assumptions about user emotions and behaviours have also led to design errors, in some instances exacerbating the very social problems the plans were intended to address. For example, 'towers in the park' designs for urban housing, popularised following World War I by urban designer Le Corbusier and others, sought to afford weary workers with the restorative aspects of nature. Writing in 1929, Le Corbusier explained the primacy of open spaces in his designs: 'work in our modern world becomes more intensified day by day, and its demands affect our nervous system in a way that grows more and more dangerous. Modern toil demands quiet and fresh air, not stale air. The towns of today can only increase in density at the expense of the open spaces, which are the lungs of the city' (Le Corbusier, 1987; p. 167). These ideals were incorporated into major urban plans of time, including public housing developments in the United States; in the American experience, it was found that instead of alleviating the stresses and social challenges of the urban poor, these designs concentrated them in quickly stigmatised high-rise developments, many of which were eventually demolished (Hoffman, 1996). Yet the issue of chronically stressful neighbourhood environments, due to high rates of crime, noise and air pollution, and low-quality or unstable housing conditions, extends far beyond those designed within explicitly moral environmentalist paradigms (Lorenc, et al., 2013; Gong et al., 2016; Śliwińska-Kowalska and Zaborowski, 2017). These persistent challenges faced by modern planners and urban policymakers highlight a need for interdisciplinary approaches to ensure that research does not in fact exacerbate the problem of urban stress, and the opportunities for methodological development in this field.

\section{Principles for Citizen Social Science}

This diversity of defining and measuring stress has not stemmed popular or scientific interest in its application to technologically sensing the urban experiences, emotions and environmental stressors of individuals and populations (Mukhopadhyay, 2015; Can et al., 2019). The promise of real or near-time public feedback inherent in crowd-sourced or otherwise electronically volunteered data is an attractive opportunity to evaluate the impact of interventions, including those to the built environment and workplace stress (Betti et al., 2018), to assess opportunities for adaptation or improvement, or justify urban design and planning initiatives with 'objective' data.

Wearable biosensors are seen as attractive because they enable the continuous stream of physiological data with a high temporal resolution during daily routines in real-life situations (Healey and Picard, 2005). This resolution is not possible to be obtained with one-time measurements or self-reported questionnaires (Birenboim et al., 2019). In addition, sensor methods are seen to promise a lower level of 'bias' than that of psychometric instruments and scales (Acerbi et al., 2017; Betti et al., 2018; Birenboim et al., 2019; Wilhelm and Grossman, 2010). Furthermore, the unobtrusive design of wearable sensors has provided significant potential for real-world field studies without restricting participants' mobility or routine (Birenboim et al., 2019; Mukhopadhyay, 2015; Wilhelm and Grossman, 2010; Zangróniz et al., 2017).

Simultaneous trends in data science toward 'digital fingerprinting,' or the creation and marketing of user and/or device- 
specific consumer profiles based on data inputs (e.g., geolocation, purchasing history, social media activity, smartphone use patterns, etc.) raise ethical concerns about how Citizen Science might be applied or commodified in various settings (Weber and Thouvenin, 2017). Indeed, in many contexts, consumer protections for digital data are still inadequate and fail to enforce key privacy principles and rights, such as the right to be forgotten (Thorun and Diels, 2019). Given the potential influence of these forces, it is necessary to consider how Citizen Science used for the purposes of understanding urban stress and human emotions can maintain standards of rigorous and ethical social science research. Here, we consider ethical principles regarding the data/privacy rights of participants, and recognise the practical, ethical, and scientific limits inherent in both Citizen Science methodologies and existing measures of human emotion.

Ethics. Typically, wearable physiological sensors are combined with 'human-as-sensor' software applications to gain an objective and subjective insight of urban emotions through a Citizen Science approach, alongside spatio-temporal data. However, these data can be private, sensitive or confidential information. Therefore, guidelines must be followed to preserve participants' privacy at every step of the research process. First, participants must be aware of essential elements of research such as the purpose, the procedures or the study area and they must have the possibility to withdraw at any time. Second, data storage without pseudonyms and with restricted access to data sets increase participants' privacy.

Security issues also arise with sensing devices. Tracking subjective observations are typically performed using smartphone 'human-as-sensor' applications. A key privacy principle thererore is to ensure these applications do not contain third-party code, to avoid disclosure of sensed data. Using code developed exclusively by the research team is one way to mitigate this issues, though requires advanced technical expertise. The data should be stored locally and encrypted to prevent security risks during transmission to cloud storage. Despite the ready availabilty of cheap sensors and citizen's own use and familiarity with them, rigorous Citizen Science research on urban emotion sensing should use professional products, purchased from specialised sensor companies to avoid any data security risk. Lastly, in the case of data sharing with other institutions or researchers, licensing agreements must be prepared, and restricted access must be assured (Kounadi and Resch, 2018).

While Citizen Science research projects may ostensibly offer participants full ownership of their data, the operational effectiveness of this commitment is not always clear, especially as data may be aggregated and re-aggregated by researchers. Thus, the end-result of a Citizen Scientist's participation, including the data they generate and contribute, may not be entirely clear at the time informed consent is requested. While 'open science' frameworks aim to move research toward greater transparency and replicability through data sharing, they may also present challenges to researchers hoping to remotely engage diverse groups of Citizen Scientists. If, for instance, a Citizen Scientist's geocoded contributions become part of an online data repository, how can researchers preserve the right to be forgotten? Again, these concerns are not uncommon to social science research more generally, though they take on special significance in the context of the rapidly growing field of Citizen Science, especially for models that seek to form reciprocal and mutually beneficial relationships between researchers and participants (Banks et al., 2013; King et al., 2019).
Participation. Not all public participation is the same, and have traditionally been described somewhere along a spectrum from non-participation (manipulation and therapy) to tokenism (informing, consultation, and placation) and citizen control (partnership, delegation, and citizen control) (Arnstein, 1969). While academics and policymakers have sought to develop new ways of engaging the public in evaluation and research activities through Citizen Science, highly interested and motivated individuals also engage in 'DIY' data collection, sometimes for the purposes of organising and activism, but also to satisfy curiosity or achieve personal goals. The 'quantified self movement offers notable examples of individuals who self-track daily activities, productivity, diet, microaggressions, blood glucose, to name just a few (Swan, 2012). While highly individualistic in nature, some collaborative projects have also emerged as self-trackers have shared findings in virtual communities (Barrett et al., 2013). These examples suggest we might expect some contributions to Citizen Social Science to come from highly motivated and techsavvy individuals with pre-existing motives for participating in these kinds of research activities, though perhaps as data gathering and self-tracking technologies become more accessible and ubiquitous, barriers (real or perceived) to and incentive structures for participation may change. Still, as several Citizen Science studies have noted, the potential of Citizen Science activities to stimulate or encourage broader civic participation and engagement among participants might also be leveraged to achieve broader individual, social, and community-level outcomes (Dickinson et al., 2012; King et al., 2019; Ottinger, 2016; O’Mara Eves et al., 2013; Pandya, 2012).

In 2015, the European Citizen Science Association published Ten Principles of Citizen Science, which addresses key issues surrounding citizen participation, agenda-setting, and responsibility (ECSA, 2015). Eitzel et al. (2017) have described the importance of Citizen Science terminology in the process of knowledge generation and dissemination, especially considering the increasingly international, multi-cultural, multi-disciplinary and multi-lingual interest in the topic, and summarise a wideranging set of terms and concepts commonly used by those claiming to do it. Citizen Science can be broadly classified into two strands: a 'democratic' Citizen Science, characterised by 'responsibility of science to society,' and 'participatory' Citizen Science, where individuals 'contribute observations or efforts to the scientific enterprise' (Cooper and Lewenstein, 2016, cited in Eitzel et al., 2017, p. 6). Different kinds of Citizen Science can be distinguished by clearly articulating what exactly is being done (e.g., research, monitoring, crowdsourcing, etc.), who are the 'scientists' (e.g., civic educator, commercial scientist, elite, researcher, scientist-activist, volunteer scientist, etc.) and who are the 'citizens' (e.g., amateur, anonymous, citizen, collaborator, community member, donor, human sensor, lay knowledge holder, participant, partner, student, etc.), as well as the relationships among and between these parties (Eitzel et al., 2017).

Writing from a perspective of community health research, King et al. (2016, p. 4) define three general categories for Citizen Science: 'by the people, for the people, and with the people'. These classifications are driven by differences in how projects are planned, how data are collected, interpreted, and used, and the primary target of scientific enquiry (here, focused on drivers of health). 'For the people' Citizen Science is primarily led by scientists who solicit, collect, analyse, and interpret volunteered specimens or data from human participants, including passive data collection from wearable sensors or smartphone applications, to answer questions about individual-level influences of health outcomes (e.g., global disparities in daily step counts across 
demographic groups and geographic regions) (Althoff et al., 2017). Citizen science 'with the people' begins to integrate more active participation from citizen scientists, who might volunteer personal data or assist with complex crowd-sourced tasks in ways that might promote learning (e.g., citizen scientists share heart rate data from an Apple Watch with researchers via an app that helps them interpret personal results). Finally, 'by the people' Citizen Science represents the most participatory of the approaches, whereby community members help frame research questions with scientists, collect and interpret data, and articulate findings and community priorities. Examples in practice include the Our Voice Citizen Science model used by King and colleagues, as well as community health improvement process models (Davis et al., 2014; Hinckson et al., 2017). This paradigm aligns well with other articulations of Citizen Science for social action, where research questions are set by the community (Ottinger, 2016) and citizen scientists can be engaged in all parts of the research process, from specifying research questions to dissemination of findings.

Making scientific constructs social. Bearing these ethical and democratic issues in mind, how might Citizen Social Science grapple with the ambiguous construct of urban stress and emotion? How might the definitional debates outlined above be socialised, and what kind of conciliatory strategies can mixedmethod research offer? Several opportunities are worth briefly noting. First, Citizen Science offers researchers a relatively flexible means of engaging with participants, ranging from fairly prescribed modes of participation (e.g., submitting app-based forms, geotagging incidents, volunteering physiological data etc.) to more open-ended (e.g., recording audio narratives, interview methods, participatory workshops). Thus, while researchers who have fairly well-defined constructs based upon prior work may opt for prescriptive approaches to Citizen Science, those seeking to build new theories about emotions based on observations may prefer an open-ended, inductive and interpretive approach. More collaborative models of Citizen Science should offer ways of eliciting both individual and group-level experiences with urban stress and emotion.

These considerations and their attendant principles are becoming ever more salient as our ability to generate, share, store, and analyse vast quantities of individual data is accelerated by new technologies and the commodification of user data. Selftracking has been said to fundamentally shift how people engage with their own bodies and personal data, with them 'being invited to engage with this information in some manner as part of optimising and improving their lives' (Lupton, 2016, p. 103). Lupton notes new forms of 'dataveillance', which can lead to 'function creep' whereby individuals are ostensibly encouraged to self-track by institutions such as workplaces, health and education providers, Citizen Science initiatives, the military and urban planners. Social scientists therefore have a key role to play in distinguishing between different kinds of self-tracking, ranging from: 'private, communal, pushed, imposed and exploited' (Lupton, 2016, p. 101), as well as addressing the aforementioned privacy concerns and data practices, and dealing with the individualising conception of the self implicitly advanced by such technologies. The remainder of the paper describes an approach to research design to explore the feasibility of putting these principles into practice.

\section{A mixed-methods study for analysing workplace and commuter stress}

We developed an interdisciplinary, mixed-method protocol for a study of workplace and commuter stress for university employees in Birmingham (UK) and Salzburg (Austria), with 31 participants. The study aimed to ascertain both the psychophysiological and experiential qualities of stressful experiences using methods including: biosensing (Empatica wristband); paper activity diaries (which tracked the participant's activities); two questionnaires focusing on wellbeing and stress (WHO's Quality of Life [WHOQoL BREF] survey and the Perceived Stress Scale [PSS]); and in-depth interviews. The study described was granted ethical approval by the University of Birmingham (November 2017: ERN_17-1224 09). Informed consent was obtained from all participants.

We conducted population level data analysis in Birmingham and Salzburg in order to develop a methodology for identifying 'moments of stress' in a laboratory setting, and to assess the consistency of the outcomes measures we used. Previous studies providing population level data analysis in the emergent literature on geo-located biosensing studies rely on subjective self-reported data to identify specific expressed emotions. For example, Zeile et al. (2016) examined cyclists' perceptions of safety in urban transit to map spaces in which cyclists experience negative emotional arousal, using the gradient of electrodermal activity and simultaneous geo-located video footage. Shoval et al. (2018) identified emotive spaces for tourists in Jerusalem by normalising the aggregated biosensing data using $\mathrm{z}$-scores. There is almost no research using biosensing to investigate urban wellbeing (for an exception see Winz and Söderström, 2020). We explored spatiotemporal differences in stress such as the influence of commute duration and type, differences between the two cities, and differences between the journey to and from work, and during the working day. This adds a physiological dimension to research, which has shown that longer commutes, and commuting by car can have a detrimental effect on stress and wellbeing (Chatterjee et al., 2020).

However, our study was not aimed at aggregating individual data, but instead explored the temporalities, spatialities, and psychophysiologies of the 'moments of stress' (Kyriakou et al., 2019) for each individual participant and allowed us to see how the various aspects of stress map together (Fig. 1). There was a concerted effort to combine the real-time and physiological affordances of wearable biosensing technologies, with methods, which could incorporate perceptions, coping and appraisal of stress, in relation to socially contextual factors identified, for instance in the WHOQoL survey, or by participants themselves. As we noted above, this was important given the diverse temporalities of stress-from daily hassles to life events, and their diverse spatialities-from proximate environmental stimuli to chronic exposure to stressors across the lifecourse.

In our study, research participants had the opportunity to express their perceived level of stress over the course of their commuting journey and the working day, as well as the longerterm drivers of stress that they experienced. For instance, one participant talked about how their interpretation of the contemporary political and economic context, and a perception of inequality and injustice, shaped their current responsiveness to stress:

I think, yeah, there is a lot of politics that does stress me out like not being able to afford to buy a house and that kind of stuff, I do get stressed about that kind of thing but I've never fallen in a category that gets the support or something. I mean like I'm not, people that get things without earning them and stuff, you know, scroungers, that sort of stuff does probably stress me out a little bit and when things are really unfair. (Female, age 30-40, Birmingham). 


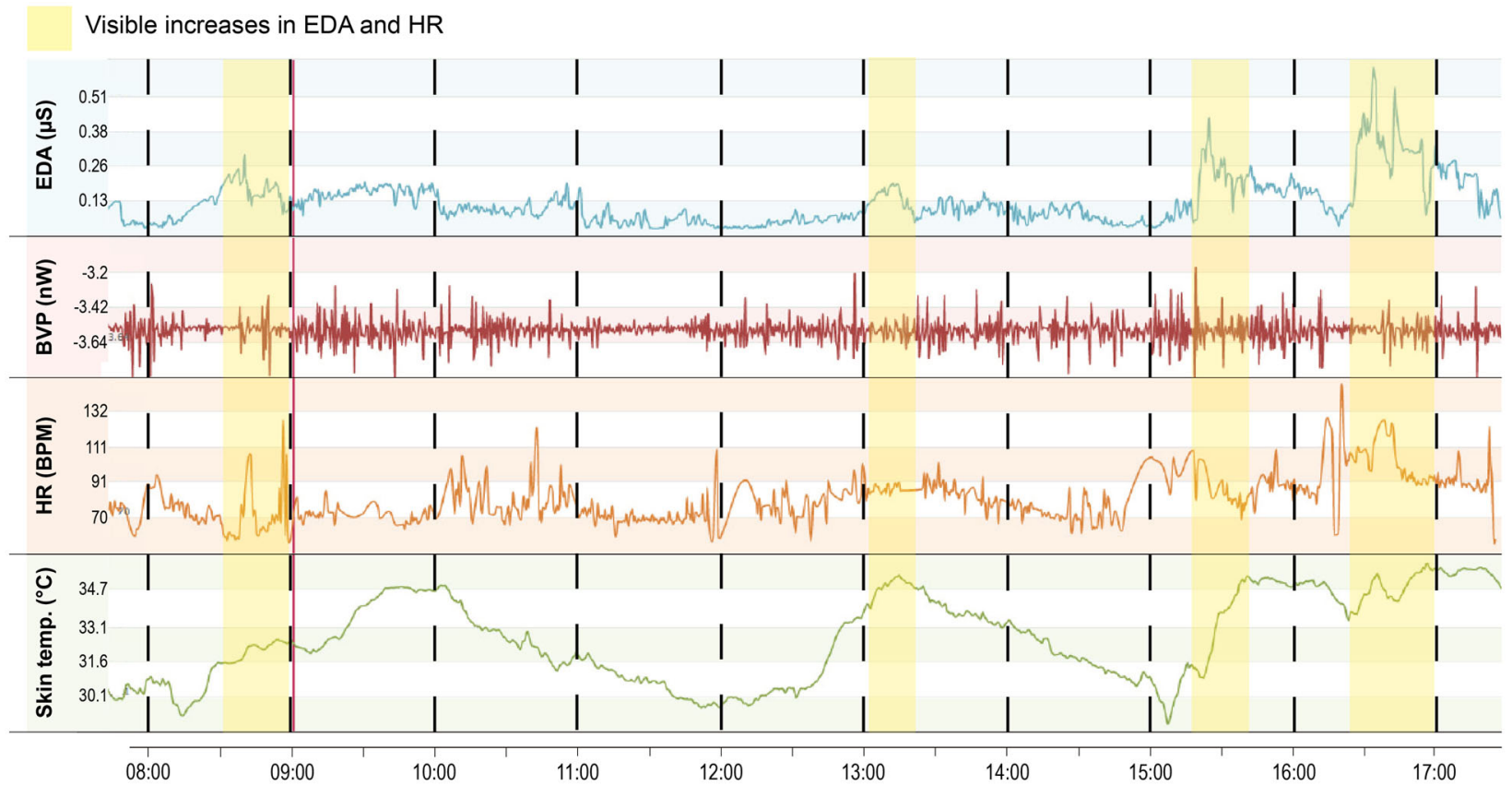

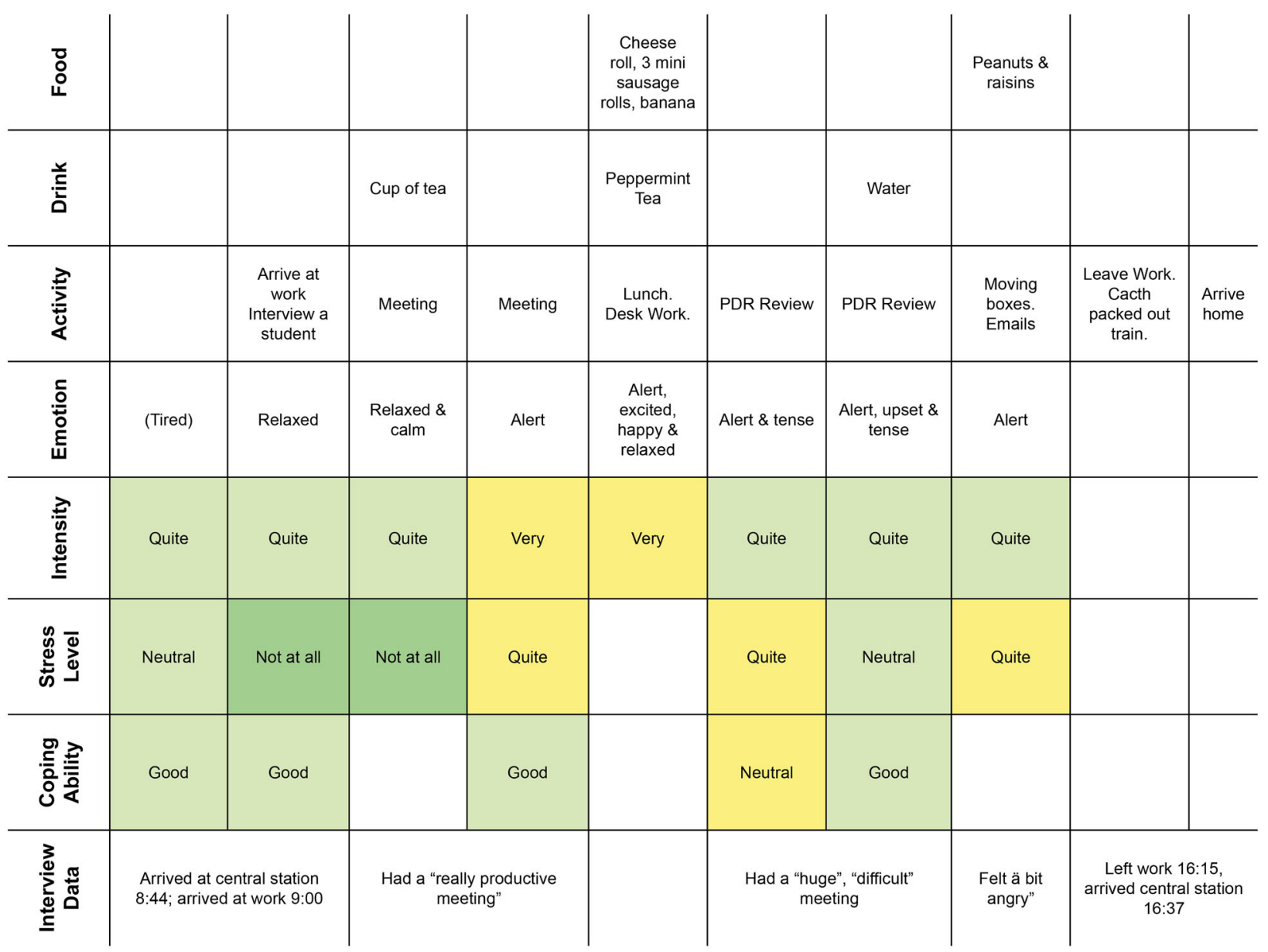

Fig. 1 Example of participant data output form. Reproduced from Pykett et al. (2020).

This interpretation highlights how social determinants of chronic exposure to the stressor of economic inequality, and potentially an embodied classed identity could be important factors shaping urban stress for this participant. These rich qualitative narratives provided a context for the biosensing data.
Osborne and Jones (2017, p. 168) argue that 'biosensing data taken in isolation tells us the what but not the why'. This crucial stage of interpretation suggests a need to enrich data sets from biosensors with methods that give a more democratic voice to research participants, including interviews and participatory 
methods. This is exemplified in the Citizen Science 'by the people' approach advanced by King et al. (2016).

In our study, the very wearing of the biosensing wristband seemed to encourage participants to reflect on their embodied responses to stressful events, and the interviews were able to draw out participant-led explanations of the drivers of stress and their complex spatio-temporalities. One participant for example described both his immediate embodied experience of stress and reflected on how his awareness of this was shaped by a previous (and elsewhere) period of depression and his expectations for control:

'I get a boost of adrenaline because you feel that fight flight mechanism going. I feel like this stuff is starting to bug me and then I think about how can I resolve this. It's not always out of my control but I've learnt to accept that I can't control everything but it's about not letting it distract me from everything else. But I think that if I hadn't had those [past] experiences at [global technology company] where I was almost on that depression state, I don't think I would have come to that realisation'. (Male, age 30-40, Birmingham).

This imperative towards valuing participants' subjective narratives contrasts with the traditional search for objectivity and generalisability in much psychophysiological research.

Similarly combining these approaches, but achieving more of a participatory Citizen Science approach than our study, Nold (2009), used geo-located biosensing data (using a sensor of electrodermal activity) to elicit place-based emotional narratives among citizen scientists during participatory mapping workshops. Nold produced maps showing the peaks and troughs in data on electrodermal activity as a proxy measure of emotional arousal, and asked his participants to talk through their reactions. In doing so, he was able to actively engage the participants, reducing the power imbalance between the researcher as 'expert' and the researched as 'data vessels'.

Like more established methods of photo-elicitation, this novel kind of 'bio-elicitation' has the potential to increase the agency of the participants in the data collection process but also in the framing of the research by enabling them to determine and add foci (Ortega-Alcazar and Dyck, 2012). Crucially, this collaborative approach to research stimulates and promotes a space of learning between researchers and participants since it is acknowledged that the participants are experts on their own lives (Kolb, 2008). As such, data is produced from multiple views and perspectives, negotiation and reflexivity, and collaborative exploration on a topic. We argue that to advance Citizen Social Science approaches to urban emotion sensing research, future study protocols should at a minimum, therefore, include opportunities for research participants to be actively involved in interpretation and analysis of their own data. Establishing effective practices for researchers to support participants should be a priority in research intended to improve urban wellbeing.

\section{Conclusion: implications for researching urban wellbeing}

Developing interdisciplinary Citizen Social Science methods requires paying attention to how specific problems such as urban stress are framed both in public life and from different scientific perspectives. This challenges the idea that urban problems can be solved through research using wearable biosensing and selftracking technologies. Assessing the historical and cultural specificity of how stress is defined and measured helps to advance understanding of how it becomes a target of individualised digital interventions for promoting urban wellbeing, and points towards some of the potential unintended consequences of these trends.
This problematises the necessary reductionism of defining and measuring emotions in disciplinary silos, and can incorporate the social and contextual nature of urban experience. Urban wellbeing policies based on biosensing, neuroscientific or psychophysiological accounts of stress would generally support urban design strategies to reduce physical environmental stressors. In contrast, a mixed-method research approach opens up considerations of the societal, political, economic and cultural contexts in which the conditions for supporting urban wellbeing can be achieved. Advancing more democratic forms of Citizen Social Science on urban stress have the potential to foreground the collective action, which will be required to achieve substantive progress on improving urban wellbeing.

Tracing a lineage between wearable real-time mood tracking technologies and the development of psychological methodologies to capture affective data, Sociologist William Davies (2017) paints a particularly bleak picture of the potential impact of the dramatic new possibilities for physiological measurement and behavioural data capture. He warns that such technologies use biomarkers to convert emotions into economic objects. This not only provides a new way for companies to value and profit from emotional data, but opens the door to new technological forms of emotional management. The appeal to a direct capture of physiological emotions can result in bypassing conscious experience, memories or citizen reflection. This may paradoxically create a less human(e) account of urban stress, where emotional experience is divided from the self by a digital interface and visible dashboards. Addressing these ethical issues raised by research using wearable biosensing technology is the first step in shaping Citizen Science approaches in which data protection, security and ownership are prioritised, and participatory commitments achieved.

\section{Data availability}

The data sets analysed during the current study are available in the Dataverse repository: https://doi.org/10.7910/DVN/D2FOTT

Received: 16 September 2019; Accepted: 8 April 2020;

Published online: 06 May 2020

\section{References}

Acerbi G, Rovini E, Betti S, Tirri A, Flóra Rónai J, Sirianni A, Agrimi J, Eusebi L, Cavallo F (2017) A wearable system for stress detection through physiological data analysis. Lect Notes Electr Eng 426:31-50

Al-Barrak L, Kanjo E, Younis EM (2017) NeuroPlace: categorizing urban places according to mental states. PLoS ONE 12(9):e0183890

Althoff T, Sosič R, Hicks JL, King AC, Delp SL, Leskovec J (2017) Large-scale physical activity data reveal worldwide activity inequality. Nature 547:336

Amin A (2013) The urban condition: a challenge to social science. Public Cult 25:201-208

Arnstein SRA (1969) Ladder of citizen participation. J Am Inst Plan 35:216-224

Aspinall P, Mavros P, Coyne R, Roe J (2015) The urban brain: analysing outdoor physical activity with mobile EEG. Br J Sports Med 49(4):272-276

Banks S, Armstrong A, Carter K, Graham H, Hayward P, Henry A, Holland T, Holmes C, Lee A, McNulty A, Moore N, Nayling N, Stokoe A, Strachan A (2013) Everyday ethics in community-based participatory research. Contemp Soc Sci 8:263-277

Barker N (2017) H(A)PPY. William Heinemann, London

Barrett MA, Humblet O, Hiatt RA, Adler NE (2013) Big data and disease prevention: from quantified self to quantified communities. Big Data 1:168-175

Beer D (2018) The data gaze: capitalism, power and perception. Sage, London

Berg M (2017) Making sense with sensors: Self-tracking and the temporalities of wellbeing Digital Health 3, https://doi.org/10.1177/2055207617699767

Berger H (1929) Über das elektrenkephalogramm des menschen. Eur Arch Psychiatry Clin Neurosci 87(1):527-570

Bergner B, Exner J, Memmel M, Raslan R, Taha D, Talal M, Zeile P (2013) Human sensory assessment methods in urban planning-a case study in Alexandria. Proceedings of REAL CORP 2013. International Conference on Urban 
Planning, Regional Development and Information Society (REAL CORP-13), Planning Times, May 29-23, Rome, Italy (June 2014), pp. 407-417.

Betti S, Molino Lova R, Rovini E, Acerbi G, Santarelli L, Cabiati M, Del Ry S, Cavallo F (2018) Evaluation of an integrated system of wearable physiological sensors for stress monitoring in working environments by using biological markers. IEEE Trans Biomed Eng 65(8):1748-1758

Bhugra D, Ventriglio A, Castaldelli-Maia J, McCay L (eds) (2019) Urban mental health. Oxford University Press, Oxford

Birenboim A (2018) The influence of urban environments on our subjective momentary experiences. Environ Plan B: Urban Analytics City Sci 45 (5):915-932

Birenboim A, Dijst M, Scheepers FE, Poelman MP, Helbich M (2019) Wearables and location tracking technologies for mental-state sensing in outdoor environments. Professional Geographer 71(3):449-461

Callard F (1998) The body in theory. Environ Plan D: Soc Spac 16:387-400

Callard F (2003) Conceptualisations of agoraphobia: implications for mental health promotion. J Public Ment Health 2(4):37-45

Camargo A, Artus A, Spiers H (2018) Neuroscience for cities. Future cities catapult, centric lab and University College London. Available at: https://futurecities. catapult.org.uk/project/neuroscience-for-cities-a-playbook/ (Accessed $30 \mathrm{Jul}$ 2019)

Can YS, Chalabianloo N, Ekiz D, Ersoy C (2019) Continuous stress detection using wearable sensors in real life: algorithmic programming contest case study. Sensors 19(8):1849

Cannon WB (1932) The wisdom of the body. Norton, New York

Cardullo P, Kitchin R (2019) Smart urbanism and smart citizenship: the neoliberal logic of 'citizen-focused' smart cities in Europe. Environ Plan C: Politics Space 37(5):813-830

Carroll D (1992) Health psychology: stress, behaviour and disease. The Falmer Press, London

Chatterjee K, Chng S, Clark B, Davis A, De Vos J, Ettema D, Handy S, Martin A, Reardon L (2020) Commuting and wellbeing: a critical overview of the literature with implications for policy and future research. Transp Rev 40 (1):5-34

Cohen S, Kamarck T, Mermeistein R (1983) Perceived stress scale. J Health Soc Behav 24:386-396

Corburn J (2004) Confronting the challenges in reconnecting urban planning and public health. Am J Public Health 94:541-546

Corcoran R, Mansfield R, Giokas T, Hawkins A, Bamford L, Marshall G (2017) Places change minds: exploring the psychology of urbanicity using a brief contemplation method. SAGE Open 7(2):1-11

Culyba AJ, Branas CC, Guo W, Miller E, Ginsburg KR, Wiebe DJ (2019) Route choices and adolescent-adult connections in mitigating exposure to environmental risk factors during daily activities. J Interpers Violence, https://doi. org/10.1177/0886260519846859

Curtis A, Mills JW, Leitner M (2007) Katrina and vulnerability: the geography of stress. J Health Care Poor Undeserved 18(2):315-330

Davidson J, Milligan C (2004) Embodying emotion sensing space: introducing emotional geographies. Soc Cultural Geogr 5(4):523-532

Davies W (2017) How are we now? Real-time mood-monitoring as valuation. J Cultural Econ 10(1):34-48

Davis MM, Aromaa SMS, McGinnis PB, Ramsey K, Rollins N, Smith JJ, Beamer A, Buckley DI, Stange KC, et al. (2014) Engaging the Underserved: a process model to mobilize rural community health coalitions as partners in translational research. Clin Trans Sci 7:300-306

Dickinson JL, Shirk J, Bonter D, Bonney R, Crain RL, Martin J, Phillips T, Purcell K (2012) The current state of Citizen Science as a tool for ecological research and public engagement. Front Ecol Environ 10:291-297

ECSA (European Citizen Science Association) Ten Principles of Citizen Science. Available at: https://ecsa.citizen-science.net/sites/default/files/ecsa_ten_principles_ of_citizen_science.pdf (Accessed 12 Sept 2019)

Eitzel MV, Cappadonna JL, Santos-Lang C, Duerr RE, Virapongse A, West SE, Kyba CCM, Bowser A, Cooper CB, Sforzi A, Metcalfe AN, Harris ES, Thiel M, Haklay M, Ponciano L, Roche J, Ceccaroni L, Shilling FM, Dörler D, Heigl F, Kiessling T, Davis BY, Jiang Q (2017) Citizen science terminology matters: exploring key terms. Citiz Sci: Theory Pract 2(1):1-20

Feldman S, Conforti N, Weidenfeld J (1995) Limbic pathways and hypothalamic neurotransmitters mediating adrenocortical responses to neural stimuli. Neurosci Biobehav Rev 19(2):235-240

Fitzgerald D, Callard F (2014) Social science and neuroscience beyond interdisciplinarity: experimental entanglements. Theory, Cult Soc 32(1):3-32

Fitzgerald D, Rose N, Singh I (2017) Living Well in the Neuropolis. Sociological Rev 64(1):221-237

Fries E, Dettenborn L, Kirschbaum C (2009) The cortisol awakening response (CAR): facts and future directions. Int J Psychophysiol 72(1):67-73

Gong Y, Palmer S, Gallacher J, Marsden T, Fone D (2016) A systematic review of the relationship between objective measurements of the urban environment and psychological distress. Environ Int 1(96):48-57
Hall E (2005) 'Blood, brain and bones': taking the body seriously in the geography of health and impairment. Area 32(1):21-29

Hall P (2014) Cities of tomorrow: an intellectual history of urban planning and design since 1880. John Wiley \& Sons, Chichester

Healey JA, Picard RW (2005) Detecting stress during real-world driving tasks using physiological sensors IEEE Trans Intelligent Transp Sys 6(2):156-166

Hellhammer DH, Wuest S, Kudielka BM (2009) Salivary cortisol as a biomarker in stress research. Psychoneuroendecrinology 34:163-171

Hinckson E, Schneider M, Winter SJ, Stone E, Puhan M, Stathi A, Porter MM, Gardiner PA, Dos Santos D, et al. (2017) Citizen science applied to building healthier community environments: advancing the field through shared construct and measurement development. Int J Behav Nutr Phys Act 14:133

von Hoffman A (1996) High ambitions: the past and future of American lowincome housing policy. Hous Policy Debate 7:423-446

Hollands GJ, Shemilt I, Marteau TM, Jebb SA, Kelly MP, Nakamura R, Suhrcke M, Ogilvie D (2013) Altering micro-environments to change population health behaviour: towards an evidence base for choice architecture interventions. BMC Public Health 13:1218

Holmes TH, Rahe RH (1967) The social readjustment rating scale. J Psychosom Res 11(2):213-218

Howard E, Mumford L (1965) Garden cities of to-morrow. The MIT Press, London Jackson M (2013) The age of stress: science and the search for stability. Oxford University Press, Oxford

Le Corbusier (1987) The city of tomorrow and its planning. Dover Publications, New York, Translated by Frederick Etchells

Lorenc T, Petticrew M, Whitehead M, Neary D, Clayton S, Wright K, Thomson H, Cummins S, Sowden A, Renton A (2013) Fear of crime and the environment systematic review of UK qualitative evidence. BMC Public Health 1 13(1):496

King AC, Winter SJ, Chrisinger BW, Hua J, Banchoff AW (2019) Maximizing the promise of Citizen Science to advance health and prevent disease. Preventative Med 119:44-47

King AC, Winter SJ, Sheats JL, Dommarco JR (2016) Leveraging citizen science and information technology for population physical activity promotion. Transl J Am Coll Sports Med 1:30-44

Kolb B (2008) Involving, sharing, analysing: potential of the participatory photo interview. Forum: Qual Soc Res 9(3) Art. 12, http://nbn-resolving.de/urn:nbn: de:0114-fqs0803127

Kounadi O, Resch B (2018) A geoprivacy by design guideline for research campaigns that use participatory sensing data. J Empir Res Hum Res Ethics 13 (3):203-222

Kreibig SD (2010) Autonomic nervous system activity in emotion: a review. Biol Psychol 84:394-421

Kyriakou K, Resch B, Sagl G, Petutschnig A, Werner C, Niederseer D, Liedlgruber M, Wilhelm F, Osborne T, Pykett J (2019) Detecting moments of stress from measurements of wearable physiological sensors. Sensors 19(17):3805

Lazarus RS, Cohen JB (1977) Environmental stress. In: Altman I, Wohlwill JF (eds) Human behavior and environment. Springer, Boston

Lazarus RS, Folkman S (1984) Stress, coping and adaptation. Springer, New York

Lederbogen F, Kirsch P, Haddad L, Streit F, Tost H, Schuch P, Meyer-Lindenberg A (2011) City living and urban upbringing affect neural social stress processing in humans. Nature 474(7352):498

Lewis PA, Critchley HD, Rotshtein P, Dolan RJ (2006) Neural correlates of processing valence and arousal in affective words. Cereb Cortex 17(3):742-748

Littlefield MM (2018) Instrumental intimacy. EEG wearables and neuroscientific control. John Hopkins University Press, Baltimore

Loh M, Sarigiannis D, Gotti A, Karakitsios S, Pronk A, Kuijpers E, AnnesiMaesano I, Baiz N, Madureira J, Oliveira Fernandes E, Jerrett M, Cherrie JW (2017) How sensors might help define the external exposome. Environ Res Public Health 14(4):434

Lupton D (2016) The diverse domains of quantified selves: self-tracking modes and dataveillance. Econ Soc 45(1):101-122

MacKerron G, Mourato S (2013) Happiness is greater in natural environments. Glob Environ Change 23(5):992-1000

Manning N (2019) Sociology, biology and mechanisms in urban mental health. Soc Theory Health 17(1):1-22

Marquardt G (2011) Wayfinding for people with dementia: a review of the role of architectural design. Herd 4:75-90

Mavros P, Austwick MZ, Smith AH (2016) Geo-EEG: towards the use of EEG in the study of urban behaviour. Appl Spat Anal Policy 9(2):191-212

Meloni M, Cromby J, Fitzgerald D, Lloyd S (2018) Introducing the new biosocial landscape. In: Meloni M, Cromby J, Fitzgerald D, Lloyd S (eds) The Palgrave handbook of biology and society. Palgrave, London, pp. 1-22

Mukhopadhyay S (2015) Wearable sensors for human activity monitoring: a review. IEEE Sens J 15(3):1321-1330

Nold C (2009) Emotional cartography: technologies of the self. Avaiable at: http:// emotionalcartography.net/ (Accessed 12 Sept 2019)

Norman GJ, Necka E, Berntson GG The psychophysiology of emotions. In: Meiselman HL (ed) Emotion measurement. Woodhead Publishing, pp. 83-98 
Olafsdottir G, Cloke P, Vögelea C (2017) Place, green exercise and stress: an exploration of lived experience and restorative effects. Health Place 46:358-365

O’Mara-Eves A, Brunton G, McDaid D, Oliver S, Kavanagh J, Jamal F, Matosevic T, Harden A, Thomas J (2013) Community engagement to reduce inequalities in health: a systematic review, meta-analysis and economic analysis. Public Health Res 1(4)

Ortega-Alcazar I, Dyck I (2012) Migrant narratives of health and well-being: challenging 'othering' processes through photo-elicitation interviews. Crit Soc Policy 32(1):106-125

Osborne T, Jones PI (2017) Biosensing and geography: A mixed methods approach. Appl Geogr 87:160-169

Ottinger G (2016) Social movement-based citizen science. In: Cavalier D, Kennedy EB (eds) The rightful place of science: citizen science. consortium for science, policy, and outcomes, Tempe, AZ: pp. 89-103

Pandya RE (2012) A framework for engaging diverse communities in Citizen Science in the US. Front Ecol Environ 10:314-317

Phan KL, Taylor SF, Welsh RC, Ho SH, Britton JC, Liberzon I (2004) Neural correlates of individual ratings of emotional salience: a trial-related fMRI study. Neuroimage 21(2):768-780

Piekut A, Valentine G (2017) Spaces of encounter and attitudes towards difference: a comparative study of two European cities. Soc Sci Res 62:175-188

Plamper J (2012) The history of emotions. an introduction. Oxford University Press, Oxford

Prior L, Manley D, Sabel CE (2018) Biosocial health geography: New 'exposomic' geographies of health and place. Prog Hum Geogr 43(3):531-552

Pykett J, Osborne T, Resch B (2020) From urban stress to neurourbanism: how should we research city wellbeing? Ann Assoc Am Geograp (in press). https:// doi.org/10.1080/24694452.2020.1736982

Richaud L, Amin A (2019) Mental health, subjectivity and the city: an ethnography of migrant stress in Shanghai. Int Health 11(1):S7-S13

Roe J, Thompson C, Aspinall P, Brewer M, Duff E, Miller D, Clow A (2013) Green space and stress: evidence from cortisol measures in deprived urban communities. Int J Environ Res Public Health 10(9):4086-4103

Rose N (2013) The human sciences in a biological age. Theory, Cult Soc 30(1):3-34

Ruppert E (2012) The governmental topologies of database devices. Theory, Cult Soc 29:116

Sandercock L (2003) Out of the closet: the importance of stories and storytelling in planning practice. Plan Theory Pract 4:11-28

Sandercock L (2004) Towards a planning imagination for the 21st Century. J Am Plan Assoc 70:133-141

Selye H (1964) The stress of life-new focal point for understanding accidents. Ind Med Surg 33:621-625

Shoval N, Schvimer Y, Tamir M (2018) Tracking technologies and urban analysis: adding the emotional dimension. Cities 72(1240):34-42

Simonsen K (2007) Practice, spatiality and embodied emotions: an outline of a geography of practice. Hum Aff 17(2):168-181

Śliwińska-Kowalska M, Zaborowski K (2017) WHO environmental noise guidelines for the European region: a systematic review on environmental noise and permanent hearing loss and tinnitus. Int J Environ Res Public Health 14 (10):1139

Steinheuser V, Ackermann K, Schönfeld P, Schwabe L (2014) Stress and the city: impact of urban upbringing on the (re) activity of the hypothalamuspituitary-adrenal axis. Psychosom Med 76(9):678-685

Swan M (2012) Sensor mania! the internet of things, wearable computing, objective metrics, and the quantified self 2.0. J Sens Actuator Netw 1(3):217-253

Thaler RH, Sunstein C (2008) Nudge. Improving decisions about health, wealth and happiness. Penguin, London

Thorun C, Diels J (2019) Consumer protection technologies: an investigation into the potentials of new digital technologies for consumer policy. J Consumer Policy https://doi.org/10.1007/s10603-019-09411-6

Vassos E, Pederson C, Murray R, Collier D, Lewis C (2012) Meta-analysis of the association of urbanicity with schizophrenia. Schizophrenia Bull $38: 1118-1123$
Ward Thompson C, Roe J, Aspinall P, Mitchell R, Clowd A, Miller D (2012) More green space is linked to less stress in deprived communities: Evidence from salivary cortisol patterns. Landsc Urban Plan 105(3):221-229

Weber RH, Thouvenin F (2017) The legal and ethical aspects of collecting and using information about the consumer. In: Siegert G, Bjørn RM, Grubenmann $\mathrm{S}$ (eds) Commercial communication in the digital age: information or disinformation? De Gruyter, Berlin, Boston, pp. 161-182

Werner C, Resch B, Loidl M (2019) Evaluating urban bicycle infrastructures through intersubjectivity of stress sensations derived from physiological measurements. ISPRS Int J Geo-Inf 8(6):265

WHO (World Health Organization) (2017) Depression and other common mental disorders. global health estimates. World Health Organization, Geneva

WHO (World Health Organization) (2018) Healthier and happier cities for all. A transformative approach for safe, inclusive, sustainable and resilient societies. World Health Organization Regional Office for Europe, Copenhagen

Wilhelm FH, Grossman P (2010) Emotions beyond the laboratory: theoretical fundaments, study design, and analytic strategies for advanced ambulatory assessment. Biol Psychol 84(3):552-569

Wilson HF (2017) On geography and encounter: Bodies, borders, and difference. Prog Hum Geogr 41(4):451-471

Winz M, Söderström O (2020) How environments get to the skin. Investigating the relation between psychosis and the city through bio-sensory ethnography. Biosocieties, forthcoming

Zangróniz R, Martínez-Rodrigo A, Pastor JM, López MT, Fernández-Caballero A (2017) Electrodermal activity sensor for classification of calm/distress condition. Sensors 17(10):1-14

Zeile P, Resch B, Loidl M, Petutschnig A (2016) Urban emotions cycling experience-enriching traffic planning for cyclists with human sensor data. GI_Forum-J Geographic Inf Sci 1:204-216

Zeisel J (2006) Inquiry by design. Environment/behaviour/neurosccience in architecture. Interiors, landscape, and planning, 2nd edn. W.W. Norton and Company, London

\section{Competing interests}

The authors declare no competing interests.

\section{Additional information}

Correspondence and requests for materials should be addressed to J.P.

Reprints and permission information is available at http://www.nature.com/reprints

Publisher's note Springer Nature remains neutral with regard to jurisdictional claims in published maps and institutional affiliations.

Open Access This article is licensed under a Creative Commons Attribution 4.0 International License, which permits use, sharing, adaptation, distribution and reproduction in any medium or format, as long as you give appropriate credit to the original author(s) and the source, provide a link to the Creative Commons license, and indicate if changes were made. The images or other third party material in this article are included in the article's Creative Commons license, unless indicated otherwise in a credit line to the material. If material is not included in the article's Creative Commons license and your intended use is not permitted by statutory regulation or exceeds the permitted use, you will need to obtain permission directly from the copyright holder. To view a copy of this license, visit http://creativecommons.org/ licenses/by/4.0/

(C) The Author(s) 2020 